\title{
NOTAS
}

\section{PARA LA FECHA DE LAS CIVILIDADES}

En un artículo reciente Ynduráin ha subrayado las semejanzas que existen entre Las civilidades, entremés de Quiñones de Benavente, y la Dedicatoria del Cuento de cuentos de Quevedo. Presenta como "hipótesis muy probable, resultado de una convicción moral, no de evidencia probada puntualmente", su opinión de que "Quevedo ha sido el expoliado"1. $\mathrm{Al}$ ofrecer esta hipótesis, Ynduráin hace constar el principal inconveniente que encuentra: la Dedicatoria lleva fecha de 1626, mientras que el entremés suele fecharse en 1609 . De un estudio sobre el entremesista, preparado hace tiempo pero no publicado aún, voy a entresacar algunos datos que demuestran que el entremés de Quiñones es muy posterior a 1609 . Con ello se desvanecen las dificultades que veía Ynduráin.

La fecha de 1609 , sobre la cual se han edificado hipótesis mucho más ambiciosas que la presente, se basa en un simple descuido de La Barrera, nunca enmendado por los eruditos ${ }^{2}$ que lo han citado, aunque era fácil descubrirlo. Dice el insigne bibliógrafo, s. v. Benavente (Catálogo, p. 31): "Ya en r6og citaba su entremés de Las civilidades don Juan Antonio de Vera y Zúñiga (después Conde de la Roca), en carta dirigida a don Juan de Fonseca y Figueroa, fecha de Sevilla, a 17 de agosto, expresando que le había compuesto un amigo suyo, pero que aún no había sido representado". La carta se conserva todavía en la B. N. M. ${ }^{3}$; una lectura detenida revela que el entremés a que alude el Conde de la Roca no es el de Quiñones, sino otro enteramente distinto.

El Conde había mandado dos sonetos suyos a Fonseca, quien se los devolvió con anotaciones marginales; el autor se defiende contra las críticas del amigo, apoyándose, según solía hacerse, en citas de los clásicos. Fonseca ha objetado el empleo de peregrino y peregrina en dos versos muy cercanos entre sí, y el Conde contesta citando a Garcilaso (Égloga II, 847-848): "QQuál me tienes la mano, de apretarme / con esa dura mano, descreído!" Y añade (f. 15o):

${ }^{1}$ F. YNDURÁrn, "Refranes y efrases hechas en la estimativa literaria del siglo xvir", $A F A, 7$ (1955), pp. 116, 118.

${ }^{2}$ F. C. SÁINZ DE Robles, El teatro español. Historia y. antologia (desde el siglo xiv al xix), t. 4 , Madrid, 1942 , p. 584 , es casi el único que propone una fecha distinta: sitúa la pieza en 1612 .

${ }^{3}$ Expreso aquí mi agradecimiento a don Erasmo Buceta por su observación de que el ms., antes designado Q-87, lleva hoy la signatura 5781 , y esta nota: "Se trata de un volumen facticio, formado con materiales, al parecer, de diversas procedencias"; y a don Tomás Magallón por haberme facilitado gentilmente una fotocopia de la carta, que se halla en los fols. $147^{-1} 5^{2}$. 
aduierta Vm. que en un entremés que escriuió vn amigo mío, aunque no se a reçitado, que trata en él de varios géneros de discretos, llama "çibilidades" a estos cuidados de apartar las bozes mesmas o juntarlas jugando de su sinificado.

Se notará en seguida: I) que no se menciona a Quiñones de Benavente; 2) que no se dice que el entremés lleve por titulo "las civilidades", y 3) que el entremés "trata... de varios géneros de discretos", mientras que el de Quiñones trata justamente de lo contrario, del habla vulgar.

Son las voces de jerigonza lo que Quiñones llama civilidades, no los "cuidados de apartar las bozes mesmas o juntarlas jugando de su sinificado". Estamos aquí frente a un pequeño problema semántico. Ya ha notado Ynduráin que "sería conveniente ampliar las acepciones de civilidad, con la de 'frase hecha, bordoncillo'. Parece especialización de 'vulgaridad', (p. 114, nota). Tal acepción, sin 'embargo, no encajaría bien con el uso de la palabra en la carta del Conde. Yo creo que civilidad debe entenderse en sentido menos específico: 'expresión (o costumbre) trillada'. Valgan unos ejemplos:

Para Vélez de Guevara ( $E l$ diablo cojuelo, tranco $\mathrm{x}$ ), son civilidades lo que hoy llamamos ripios:

Que para querer dormirse, sin qué ni para qué, no se diga: "Sueño me toma", ni otros versos por el consonante, como decir a rey, "porque es justísima ley", ni a padre, "porque a mi honra más cuadre", ni las demás: "a furia me provoco", "aquí para entre los dos" y otras civilidades, ni que se disculpen sin disculparse, diciendo "porque un consonante obliga a lo que el hombre no piensa".

En el romance "Cantemos civilidades", lo son los juegos de palabras formados a base de los nombres de calles madrileñas ${ }^{4}$. En Tirso de Molina son las convenciones de la comedia (Amar por señas, I, 1):

$$
\begin{aligned}
& \text { ¿Qué comedia } \\
& \text { hay, si las de España sabes, } \\
& \text { en que el gracioso no tenga } \\
& \text { privanza, contra las leyes, } \\
& \text { con duques, condes y reyes, } \\
& \text { ya venga bien, ya no venga? } \\
& \text { ¿Qué secreto no le fían? } \\
& \text { ¿Qué infanta no le da entrada? } \\
& \text { ¿A qué princesa no agrada? } \\
& \text {-Los poetas desvarían } \\
& \text { con esas civilidades, } \\
& \text { pues dando a la pluma prisa, } \\
& \text { por ocasionar la risa } \\
& \text { no excusan impropiedades. }
\end{aligned}
$$

En los entremeses Los refranes del viejo celoso y Las sombras, atribuídos a Quevedo, civilidades vale por 'vejeces', y se aplica a esos personajes folklóricos que en otras partes se llaman chistes $^{5}$. En cambio, en el Cuento

* Primavera y flor de los mejores romances, recogidos por el Licdo. Arias Pérez (Madrid, 1621), ed. de José F. Montesinos, Valencia, 1954, pp. 32-35.

5 Obras en verso, ed. Astrana Marín, Madrid, 1943, pp. 556, 561 . 
de cuentos, donde Quevedo satiriza exactamente lo mismo que Quiñones, no hallamos la palabra civilidades, como tampoco en el romance de Gabriel Lasso, "En estas cortes se pide", dedicado al mismo asunto ${ }^{6}$. Así, pues, el empleo de la palabra civilidades en la carta del Conde de la Roca, aun yuxtapuesta a "entremés", no constituye ninguna alusión a la obra de Quiñones, y la fecha de 1609 no se relaciona en absoluto con esta pieza. Quedan sin fundamento, por lo tanto, las hipótesis basadas en La Barrera: los estudios en que se toma ese año por principio de la carrera teatral de Quiñones y a partir del cual se calcula cuantitativamente su producción entremesil, la tentativa de fechar una comedia de Tirso por su alusión a Quiñones, y la atribución de una docena de entremeses más ${ }^{7}$. En cuanto al plagio evidente de que tratamos, ya no hay obstáculo para afirmar que en este caso, como en otros muchos $^{8}$, Quiñones de Benavente se inspiró en Quevedo. En Las civi-

- Manojuelo de romances (Zaragoza, 1601), ed. E. Mele y A. González Palencia, Madrid, 1942, pp. 68-70. Este romance tiene el mismo fin docente que las obras de Quevedo y de Quiñones: "En estas cortes se pide / y aun se ha propuesto otras veces / que a tetas, tripa y sobacos / destos reinos se destierren..." Sigue una larga enumeración de palabras y frases groseras, y luego: "A lo primero responden / que muy justo y conveniente / que la tosca gerigonza / como piden se destierre, / y el que della o parte usare / por preciso necio quede..." Sin duda por su antigüedad, el romance sólo coincide con el entremés en unas cuatro de sus 87 "civilidades".

${ }^{7}$ José SÁnchez-ArJona, Noticias referentes a los anales del teatro en Sevilla desde Lope de Rueda hasta fines del siglo xvii, Sevilla, 1898, p. 142, después de citar (sin declararlo) a La Barrera, supone por ello que Quiñones estuvo en Sevilla en dicho año: “...y como en el año 1607 hemos visto que formaba parte de la compañía de Alonso Riquelme un Luis de Quiñones músico y representante, pudiera sospecharse que el dicho Quiñones de Benavente autor del entremés Las civilidades estuviese en Sevilla por este tiempo, y que tal vez fuese el mismo que en 1607 formaba parte de la compañía de Riquelme".-Tanto E. Cotarelo como doña Blanca DE Los Ŕos entienden que en 1609 y con Las civilidades empezó a escribir nuestro autor. De unos versos de Tanto es lo de más como lo de menos (II, 7), donde se habla de un entremesista (casi todos creemos que el aludido es Quiñones) a quien sonríe el éxito desde hace "más de nueve o diez años", deduce Cotarelo que la comedia se compuso nueve o diez años después de 1609 (NBAE, t. 9, p. xxxviii); además, calcula que si, como afirma Tirso, el entremesista en cuestión escribió 300 piezas en los nueve o diez años mencionados, en los treinta que van de 1609 a 1639 habría compuesto unas goo (NBAE, t. 17, pp. lxxvii-lxxviii). Para doña Blanca, la fecha de la comedia es 1614, y como no caben "nueve o diez años" entre 1609 y 1614 , la alusión no puede ser a Quiñones, y la docena de entremeses allí enumerados no son suyos (Obras de Tirso, t. 1, pp. 947959 y $\left.9^{61}\right)$.

8 Todas las obras de QuiÑones que cito se encuentran en la Colección de entremeses, loas, bailes..., ed. Cotarelo, NBAE, t. 18; las de Quevedo, en la ed. de Astrana: Obras completas en prosa (2. ed., Madrid, 1941) y Obras en verso (Madrid, 1943). Hay recuerdos del Libro de todas las cosas (Prosa, p. 71) en El murmurador (p. 528a), el dudoso Las cuentas del desengaño (p. 810b), El doctor (p. 586a) y El doctor y el enfermo (p. 6o1b); del Sueño del infierno (Prosa, pp. 187-188) y de La perinola (Prosa, pp. 874-875) en Los alcaldes encontrados, $5^{\text {a }}$ parte (p. 677b); del romance "Parióme adrede mi madre" (Verso, p. 265) en El convidado (pp. 803-804); de la jácara "Carta de Escarramán a la Méndez" (Verso, p. 209) en Los planetas (p. $5^{61 b}$ ), El negrito hablador (p. 6o6b) y el apócrifo Don Gaiferos (p. 612b); de la jácara "Relación que hace un jaque de sí y de otro" (Verso, p. 223) en la loa para Prado (pp. 516-517), y de "Descubre Manzanares secretos de los que en él se bañan" (Verso, p. 293) en la misma loa (p. 517a).-Los entremeses de Quevedo El marión (1. parte) y Los refranes del viejo celoso se parecen en asunto o estilo a varias obras de Quiñones. El hacer que un grupo de hombres y mujeres, representantes de vicios populares, pasen a la vista de un personaje alegórico que los condena, técnica empleada por Quiñones no sólo en Las civi- 
lidades se señalan unas 105 expresiones, go de las cuales se hallan o en la Dedicatoria o en el texto del Cuento de cuentos. El entremés tiene además ese fin didáctico que caracteriza a la Dedicatoria. Hay una figura cómica, el doctor Alfarnaque, que se dedica a corregir el lenguaje popular:

Tontonazos, tontones, retontones, zurdos castellanicos de bullaque, yo me llamo el doctor don Alfarnaque, y de vergüenza y lástima que os tengo vuestra lengua a enseñaros a hablar vengo.

No hay que hacer burla, hablantes de poquito; que no sabéis hablar, por Dios bendito ${ }^{9}$.

En otras palabras, el entremés de Quiñones viene a ser una dramatización del Cuento de cuentos, y su fecha de composición ha de ser posterior - pero poco posterior- a la de la obra de Quevedo.

La Dedicatoria del Cuento de cuentos lleva fecha del 17 de marzo de 1626; sin embargo, el libro tardó algo en publicarse ${ }^{10}$. Las primeras ediciones conocidas son de 1629 , y en este año hay varias (Zaragoza, Pedro Verges; Valencia, Miguel de Sorolla; Barcelona, Estevan Liberós), y se incluyó en la colección Desvelos soñolientos y discursos de verdades soñadas, Barcelona (Pedro Lacavalleria), 162911. Volvió a publi-

lidades, sino también en La paga del mundo, La verdad, Las cuentas del desengaño, El sueño, La muerte, La visita de la Cárcel, El alcalde del Corral, Al cabo de los bailes mil, El martinillo, El doctor Juan Rana, El doctor, El remediador, El doctor Sánalotodo y Las malcontentas, recuerda La hora de todos y otros escritos satíricos de Quevedo.-La crítica social y moral de Quiñones, como la de Quevedo, va siempre dirigida contra las falsificaciones de la vida.

${ }^{9}$ Ed. cit., pp. 503-504. Cabe preguntarse si se ha pretendido retratar a Quevedo en el doctor Alfarnaque, que sale "con anteojos, sombrero de halda grande, ropa negra y guantes doblados". Con excepción de los anteojos, es éste el atuendo regular de los médicos de Quiñones - como de los de Quevedo-, y se sabe que el entremesista no solía satirizar a las personas. (Véase mi estudio "Una caricatura de Juan Ruiz de Alarcón", $N R F H, 8,1954$, p. 419; allí se trata de una sátira indudable en obra dudosa, pero aquí la obra es rigurosamente auténtica). Por el solo detalle de los anteojos no me atrevería a afirmar que hay sátira personal en Las civilidades.

10 Don Aureliano Fernández-Guerra sospechó que el libro se imprimió en Huesca en 1626 (BAAEE, t. 23, p. lxi; t. 48, p. 397, nota; Soc. de Biblióf. Andaluces, t. 1, Sevilla, 1897 , p. 116; cf. también su "Noticia de un precioso códice de la Biblioteca Colombina", inserta al final del t. 1 del Ensayo de Gallardo, col. 1325), pero no llegó a precisar los fundamentos de su sospecha. En las bibliografías de las dos colecciones citadas marca esta edición con asterisco, indicando así que no la ha visto. Ni Ricardo DEL ARco ("La imprenta en Huesca", RABM, 22, 1910, 223-224) ni Astrana Marín (Ob. en verso, p. 1373, nota) pudieron hallar rastro de esta edición hipotética.-Acerca de las dificultades que corrió el Cuento de cuentos con el Santo Oficio, véase $O b$. en prosa, pp. 790 ss.

${ }^{11}$ No me ha sido posible examinar personalmente estos libros; los cito por la bibliografía de Astrana, $\mathrm{Ob}$. en verso. No sé si el Cuento se incluyó en las demás ediciones de los Desvelos soñolientos (Lisboa, Luis de Souza, 1629); Pamplona, Carlos de Labayén, 1631; Sevilla, 1631; Lisboa, Mathias Rodrigues, 1633; Barcelona, Pedro Lacavalleria, 1635); por lo menos, no se incluyó en la de Zaragoza, 1627 (cf. Ob. en verso, p. 1376).-Hay una ed. sin portada ni licencias y sin año, impresa en Gerona por Gaspar Garrich y Juan Simón, que he visto en la colección de la Hispanic Society, inserta al final del Discurso de todos los diablos, o infierno enmendado (Gerona, por los mismos impresores, 1628 ), pero no ligada a él ni por paginación ni por reclamo alguno. Es una versión bastante incorrecta, en la que faltan la fecha del prólogo y una 
carse en ${ }^{16} 3_{1}$ junto con los Juguetes de la niñez (Madrid, Viuda de Alonso Martín) y con la Politica de Dios (Pamplona, Carlos de Labayén) ${ }^{12}$.

Aparte su filiación con el Cuento de cuentos, hay en Las civilidades un dato que de ningún modo nos permite postular fecha anterior a 1620. Como casi todas las obras impresas en la edición príncipe de Quiñones (Ioco seria..., Madrid, Francisco García, 1645), lleva en el encabezamiento el nombre del director de la compañía que había de representarla, y en el reparto los de algunos actores. Muchas de las piezas de ese tomo pueden fecharse con bastante exactitud gracias al estudio biográfico de los cómicos citados ${ }^{13}$, pero en el caso de Las civilidades las noticias son más escasas y sólo sirven para limitar la fecha a 1620-1634, imposibilitando algunos de los años intermedios.

Consta que la obra fue representada por Avendaño, o sea Cristóbal de Avendaño, uno de los más famosos "autores" de la época, para quien escribió Quiñones por lo menos otros seis entremeses ${ }^{14}$. Como la mayoría de sus colegas, Avendaño había empezado su carrera siendo simple representante. En 1601 trabajaba con sus padres, Lope de Salcieta Avendaño y Jerónima de Salcedo, en la compañía de Andrés de Heredia. En 1610, 1611 y 1613 lo encontramos, solo, en la de Pinedo, y en 1619, con su mujer María Candado (o Candau), en la de Tomás Fernández ${ }^{15}$. Es posible que empezara como "autor" ya entrado este año de 1619, y que participara en las fiestas del Corpus de Madrid en 1620, pero el docu-

de las "civilidades" citadas por Quiñones.-Aunque se nos asegura que el Cuento "corrió mucho en manuscrito, con grandes libertades" (Astrana, Ob, en verso, p. lv), no hay pruebas de contactos personales entre los dos escritores -la mención que hace Quevedo de [Quiñones de] Benavente en la Perinola es poco halagüeña-, de modo que lo más probable es que el entremesista se haya atenido a alguna versión impresa.

12 Astrana (Prosa, p. vi; Verso, p. 1381) niega terminantemente la existencia de una ed. de los Juguetes de 1629, postulada por Fernández-Guerra. - Creo que el Cuento volvió a publicarse en todas las ediciones de los Juguetes. A las siete enumeradas por Astrana entre 1633 y 1641 añádase la de Barcelona (M. Gracián), 1635, conservada en la B. N. P. Todas tienen los mismos preliminares: privilegio y tasa de 1631, censura de 23 de agosto de 1629 con índice del contenido, aprobación del P. Juan. Vélez Zavala del último de septiembre de 1629 [de "1626" en la ed. de Sevilla, 1634, errata evidente]. - Por las variantes que cita Fernández-Guerra de la ed. de Pamplona se ve que ésta reproduce todos los errores y omisiones de la de Gerona sin año.

13 Todas esas piezas caen entre 1627 y 1639 . De las que no llevan reparto, una - El retablo de las maravillas - parece anterior. No puedo entrar en detalles aquí; baste decir que este Retablo (basado en el de Cervantes, pero con no pocos cambios) alude a premáticas suntuarias y a la renovación de la Plaza Mayor, alusiones que tienden a situarlo entre 1620 y 1623 , probablemente en 1621 . Prescindiendo de las: que aún no pueden fecharse del todo, ésta debe de ser una de las obras más antiguas que nos quedan de Quiñones.

14 Rennert, The Spanish stage in the time of Lope de Vega, New York, 1909, pp. $426-428$, cita a varios cómicos de este apellido, pero sólo Cristóbal llegó a ser "autor".

${ }_{15}$ C. López Martínez, Teatro y comediantes sevillanos del siglo xvi. Estudio documental, Sevilla, 1940, pp. 69 y 64; C. PÉRez PAstor, Bibliografia madrileña..., Madrid, 1891-1907, t. 3, p. 325; ID., Nuevos datos acerca del histrionismo español en los siglos xvi y xuii, [1" serie], Madrid, 1901, pp. 131 y 168 . - Los contratos entre representante y "autor", firmados casi siempre a principios de la cuaresma, solían ser por solo un año. 
mento no es claro"16. Su primer año de "autor" no habrá sido muy afortunado, pues si el 16 de noviembre de 1620 contrataba representantes como "autor de comedias con título de Su Magestad", el 15 de diciembre siguiente vuelve a aparecer como simple representante en la compañía de Fernández ${ }^{17}$. En todo caso, se hallaba bien establecido en 1621 , pues en el Corpus de este año presentó al público de Madrid los autos Salomón y El llegar en ocasión ${ }^{18}$.

No hay para qué recordar aquí su larga carrera. Sólo nos interesa notar que se le menciona por última vez en un documento de 9 de julio de 1634 , y que en mayo de 1635 María Candado estaba casada con Salvador Lara ${ }^{19}$. Sin embargo, en una lista de comedias representadas ante el Rey aparecen varias hechas por Avendaño, al parecer a fines de noviembre de 1635 :

En Madrid, a 10 de octubre 1635 , a Francisco de Alegría, arrendador de los corrales de la comedia, 1,050 reales por cinco particulares que hizo a S. M. Cristóbal de Avendaño, intitulados:..., en 14 de mayo de 1634, en 21 , en 28 , en 4 y en 10 de junio dél.

En 27 de noviembre 1635 , 6oo rs. por tres particulares que hizo a S. M., intitulados:..., en 8 , en 20 y en 26 de noviembre de este año.. ${ }^{20}$

Para Restori, estas palabras prueban que sobre este punto se equivocan los libros de la Cofradía y los eruditos que en ellos se basan ${ }^{21}$. Por mi parte, no veo claro quién hizo las representaciones de noviembre, ni a qué año se refiere la palabra este (extrañaría un pago al día siguiente, en vista de la tardanza con que se pagaron las representaciones de 1634), ni, sobre todo, por qué se pagó a Alegria un dinero debido a Avendaño, a menos que éste ya hubiera muerto. Además, la lista de Villaamil no es rigurosamente cronológica y adolece de tantas erratas, en particular en las fechas, que antes de fundar toda una hipótesis en ella prefiero creer en las otras autoridades, y dar por terminada la carrera de Avendaño antes de mayo de $\mathbf{1 6} 35$.

Además del nombre del “autor", el reparto de Las civilidades nos da el de los actores siguientes: Francisco Álvarez, Luis de Cisneros, Isabel Ana, Eugenia y Ana María. Sólo los dos primeros pueden identificarse a ciencia cierta ${ }^{22}$. Francisco Alvarez de Vitoria se casó con Josefa Nieto

${ }^{16}$ J. Sánchez-Arjona, Noticias, p. 241; C. Pérez Pastor, Nuevos datos acerca del histrionismo español en los siglos xvi y xvii, $2^{*}$ serie, Bordeaux, 1914, doc. 155.

17 Pérez Pastor, Nuevos datos, $2^{\mathrm{q}}$ serie, docs. 153 y 154.

18 Pérez Pastor, Nuevos datos, [1 $1^{\mathrm{a}}$ serie], p. 188; $2^{\mathrm{a}}$ serie, docs. 155, 160, 162, 165.

19 Pérez Pastor, Nuevos datos, 2" serie, doc. 250; SÁnchez-ArJona, Noticias, pp. 294-296.-María Candado murió en Granada en agosto de 1636, como sabemos por el testamento de su madre, otorgado el 29 de diciembre de ese año, donde se declara también que tanto Avendaño como Lara han muerto (Nuevos datos, 2: serie, doc. 301). Según La Barrera (Catálogo, p. 20) y otros, el viejo libro de la Cofradía de la Novena, a la cual pertenecían todos los cómicos, afirma que Avendaño murió en 1635 .

20 G. Cruzada Villaamil, "Teatro antiguo español...", en El Averiguador, 2" época, 1 (1871), p. 74 .

21 RestorI, "Piezas de titulos de comedias". Saggi e documenti inediti o rari del teatro spagnuolo dei secoli xvii e xviii, Messina, 1903, p. 113, nota.

${ }^{22}$ En 1622 trabajaba en la compañía de Avendaño una Isabel Ana, mujer de Bartolomé Calvo de Arze (Tomillo y Pérez Pastor, Proceso de Lope de Vega por 
en Valladolid, en 1630; estuvo en la compañía de Fernández en 1631, en la de Juan Jerónimo Valenciano en 1633, y en la de Luis López en ${ }^{16} 35^{23}$; más tarde se hizo “autor”. Luis de Cisneros desempeña papeles en las dos loas que escribió Quiñones para el "autor" Figueroa, que por consiguiente no pueden ser del mismo año que Las civilidades; creo que son de 1627 y 1628; Cisneros estuvo otra vez en la compañía de Figueroa en 1631 y murió en $1634^{24}$. Aunque no tenemos ningún documento que nos diga en qué año estuvieron juntos todos estos actores en la compañía de Avendaño, los datos que poseemos nos hacen excluir, como fecha en que pudo escribirse el entremés Las civilidades, los siguientes años: 1627 y 1628 (Quiñones escribe dos loas para Figueroa, en cuya compañía trabaja Luis de Cisneros); 1631 (Francisco Alvarez y Luis de Cisneros están en otras compañías); 1633 (Álvarez trabaja en otra compañía) y 1635 (Cisneros ha muerto, y también Avendaño, en mayo o quizá antes). Quedan, pues, como únicas posibilidades los años 1620-1626, 1629, 1630 y $1632^{25}$.

Puesto que la Dedicatoria del Cuento de cuentos no se escribió hasta 1626 , y puesto que la obra alcanzó gran popularidad en 1629, como lo demuestran sus cuatro ediciones, es muy probable que su dramatización por Quiñones de Benavente se haya hecho en ese año de 1629 o en el siguiente.

Hunter College, New York.

Hannah E. de Bergman

libelos contra unos cómicos, Madrid, 1901, p. 297); Avendaño había trabajado con Valdés en 1615 y 1616 (F. DE B. SAN RomÁn, Lope de Vega, los cómicos toledanos y el poeta sastre..., Madrid, 1935, doc. 413) y después con Morales en 1624 (Nuevos datos, [ $1^{\mathrm{a}}$ serie], p. 207). Otra Isabel Ana, mujer de Jusepe Luzón, estaba en la compañía de Jerónimo Sánchez en 1623, y una Isabel Ana, viuda, en la de Juan Román en 1639 (Nuevos datos, [1: serie], pp. 194 y 299). - El nombre Ana María era muy común entre las actrices de la época. De las tres que aparecen en la compañía de Avendaño en 1632 (SÁnchez-ArJona, Noticias, p. 3oo), la más famosa era Ana María de Peralta, apodada "la Bezona" por ser mujer del gracioso Juan Bezón, la cual desempeñó papeles en dos obras de Quiñones: El doctor (Avendaño, 1629?) y la primera loa para la compañía de Figueroa (1627). - Hubo también varias Eugenias, pero hasta ahora no he visto ningún documento que nos indique cuál de ellas perteneció a la compañía de Avendaño.

${ }^{23}$ José MaRTí y Monsó, Estudios histórico-artisticos relativos principalmente a Valladolid, Valladolid y Madrid, 1901, p. 566 (no se dice en qué compañía trabajaba entonces Álvarez; es posible que fuese en la de Avendaño, porque este "autor" se hallaba en Valladolid en 163o: cf. N. ALonso CoRTÉs, El teatro en Valladolid, Madrid, 1923, p. 83); Cayetano Rosell, ed. de Quiñones de Benavente, Colección de piezas dramáticas, entremeses, loas y jácaras..., Madrid, 1872-74 (Libros de antaño), t. 2, p. 327; López MARTínez, Teatro y comediantes sevillanos, pp. go y 91.

24 E. Cotarelo, "Actores famosos del siglo xvir: Sebastián de Prado y su mujer Bernarda Ramírez", $B A E$, 2 (1915), 275 y 277, nota.

${ }^{25}$ Hay una lista de la compañía de Avendaño en 1632 (SÁnchez-ArJona, Noticias, p. 300) en la cual no figuran Francisco Álvarez, Luis de Cisneros, Isabel Ana ni Eugenia. Aunque tales listas no son tan de fiar como otros documentos, la omisión de tantos nombres extrañaría si fuese éste el año de Las civilidades. 